\title{
Effect of natural phenols on the catalytic activity of cytochrome P450 2E1
}

\author{
Renata Mikstacka ${ }^{\bowtie}$, Jerzy Gnojkowski and Wanda Baer-Dubowska \\ Department of Pharmaceutical Biochemistry, University of Medical Sciences, \\ Grunwaldzka 6, 60-780 Poznań, Poland
}

Received: 30 July, 2002; revised: 12 November, 2002; accepted: 21 November, 2002

Key words: polyphenols, tannic acid, protocatechuic acid, resveratrol, CYP2E1, inhibition kinetics, mechanism-based inhibition

\begin{abstract}
The effect of protocatechuic acid, tannic acid and trans-resveratrol on the activity of p-nitrophenol hydroxylase (PNPH), an enzymatic marker of CYP2E1, was examined in liver microsomes from acetone induced mice. trans-Resveratrol was found to be the most potent inhibitor $\left(\mathrm{IC}_{50}=18.5 \pm 0.4 \mu \mathrm{M}\right)$ of $\mathrm{PNPH}$, while protocatechuic acid had no effect on the enzyme activity. Tannic acid with $\mathrm{IC}_{50}=29.6 \pm 3.3 \mu \mathrm{M}$ showed mixedand trans-resveratrol competitive inhibition kinetics $\left(K_{\mathrm{i}}=1 \mu \mathrm{M}\right.$ and $2.1 \mu \mathrm{M}$, respectively). Moreover, trans-resveratrol produced a NADPH-dependent loss of PNPH activity, suggesting mechanism-based CYP2E1 inactivation. These results indicate that trans-resveratrol and tannic acid may modulate cytochrome P450 2E1 and influence the metabolic activation of xenobiotics mediated by this P450 isoform.
\end{abstract}

Tannic acid, protocatechuic acid and trans-resveratrol are naturally occurring phytophenols present in edible fruits and vegetables. A number of dietary polyphenols were shown to modulate the process of multistage carcinogenesis in animal models (Newmark, 1996). Protocatechuic acid, a simple phenolic acid, and a constituent of apples, green and black tea and herbal medicines, was reported to be an efficacious agent in reducing the carcinogenic action of nitrosoamines and related amino derivatives as well as dimethylbenz[a]anthracene in rats (Ohnishi et al., 1997; Mori et al., 1999; Nakamura et al., 2000). Tannic acid, a mixture of digallic acid esters of glucose, mainly present in tea, cocoa, beans, grapes, strawberries and persimmon, was shown to inhibit the mutagenicity of polycyclic aromatic hydrocarbons in Salmonella typhimurium and Chinese hamster V79 cells as well as the tumorigenicity of polycyclic aromatic hydrocarbons and $N$-methyl nitrosourea in mouse skin, lung and forestomach (Nepka et al., 1999; Chen \&

${ }^{\bowtie}$ Corresponding author: tel:. (48 61) 869 9181; e-mail: rmikstac@mail.am.poznan.pl

Abbreviations: CYP2E1, cytochrome P450 2E1; $\mathrm{Me}_{2} \mathrm{SO}$, dimethylsulfoxide; $K_{\mathrm{i}}$, equilibrium dissociation constant for enzyme-inhibitor complex; PNPH, $p$-nitrophenol hydroxylase. 
Chung, 2000). Moreover, tannic acid applied to mouse skin caused the inhibition of covalent benzo(a)pyrene-diol-epoxide binding to epidermal DNA (Baer-Dubowska et al., 1997), which is considered a critical event in the initiation stage of carcinogenesis. Resveratrol (3,5,4'-trihydroxystilbene) occurs in peanuts, grapes and herbal remedies used in Japan and China (Ignatowicz \& Baer-Dubowska, 2001). It can be found in the cis and trans configurations, either free or in a glycosylated form (Soleas et al., 1997; Burns et al., 2002). Significant concentrations $(1-10 \mu \mathrm{M})$ of the aglycons cis-and trans-resveratrol are present in red wine (Soleas et al., 2002). trans-Resveratrol has been reported to inhibit dimethylbenz[a]anthracene induced preneoplastic lesion formation in mouse (Jang et al., 1997). The suppression of $N$-nitrosomethylbenzylamine (NMBA)-induced esophageal tumorigenesis in F344 rats by resveratrol was recently reported ( $\mathrm{Li}$ et al., 2002). The antimutagenic activity of resveratrol was demonstrated against a foodborne hetero- cyclic amine, 3-amino-1,4-dimethyl-5H-pyrido[4,3-b]indole (Trp-P-1) and 2-aminofluorene in Salmonella bacterial tester strains (Uenobe et al., 1997; Gusman et al., 2001).

Most chemical carcinogens require metabolic activation catalyzed by cytochrome $\mathrm{P} 450$ in order to exert their genotoxic and carcinogenic effects. Thus one possible mechanism by which phenolic compounds might exert anticarcinogenic effects is through an interaction with the cytochrome P450 system, either by the inhibition or activation of certain forms of this enzyme, leading to a reduced production of the ultimate carcinogen (Guengerich \& Shimada, 1998; Hursting et al., 1999; Sporn \& Suh, 2000). Our previous, and other authors' studies have shown that these structurally diversified phenolics inhibit cytochromes $\mathrm{P} 450$ 1A1, 1A2 and 2B (Baer-Dubowska et al., 1998; Das et al., 1999; Chang et al., 2001).

In this paper, we have evaluated the effect of a simple phenolic acid, protocatechuic acid; a polyphenol, tannic acid and a trihydroxystilbene, trans-resveratrol (Fig. 1) on
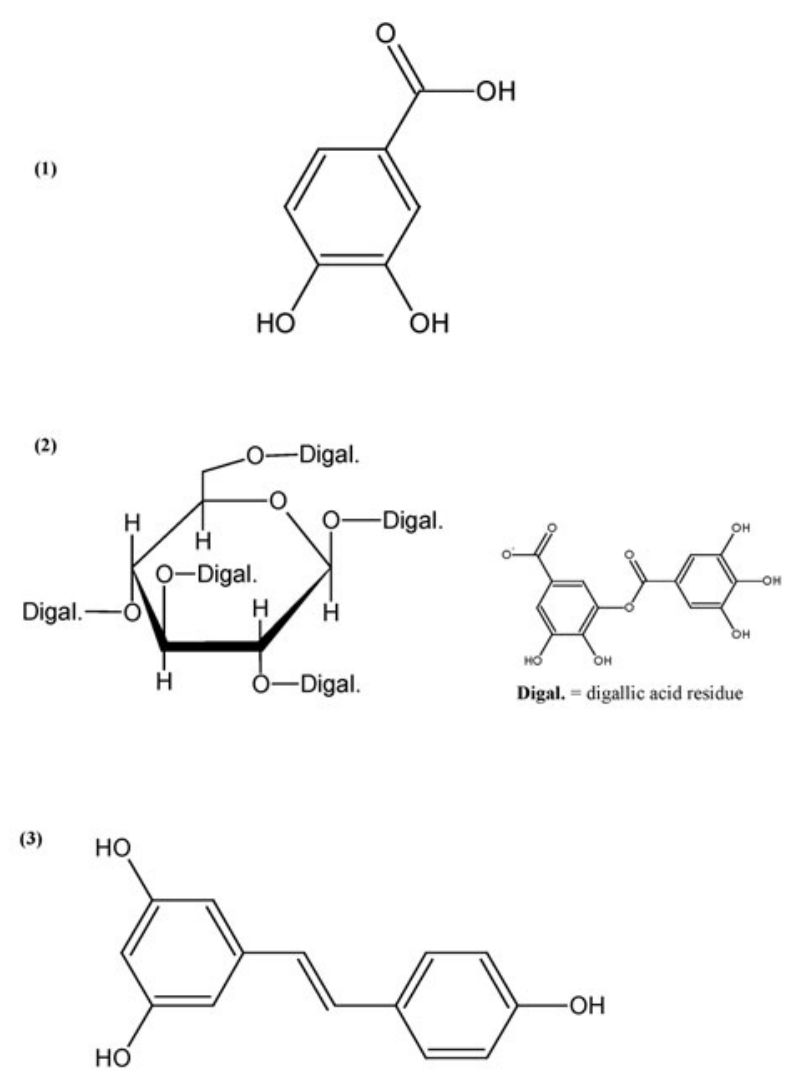

Figure 1. The structures of protocatechuic acid (1), tannic acid (2) and trans-resveratrol (3). 
murine hepatic hydroxylation of $p$-nitrophenol, which represents a selective substrate for cytochrome P450 2E1. CYP2E1 is vital in catalyzing the activation of nitrosodimethylamine, alkanes, halogenated hydrocarbons, and many other low molecular mass environmental chemicals (Guengerich et al., 1991). Inhibition of CYP2E1 is expected to block the toxicity and carcinogenicity of these compounds.

\section{MATERIALS AND METHODS}

Chemicals. Protocatechuic acid (purity 97\%), trans-resveratrol (purity 99\%), p-nitrophenol, NADP, glucose-6-phosphate and glucose-6-phosphate dehydrogenase were purchased from Sigma (St. Louis, MO, U.S.A.). Tannic acid (purity 97\%) was obtained from Aldrich (Milwaukee, WI, U.S.A.). All other compounds were commercial products of the highest purity available.

Animals, treatment and microsome preparation. Female Swiss mice (7-9 weeks old, $25 \mathrm{~g}$ ) were used in all experiments. The animals were housed in polycarbonate cages containing hardwood chip bedding at $21^{\circ} \mathrm{C}$ and with a relative humidity of $40-70 \%$. Commercial mouse food and distilled water were available ad libitum. The mice were treated intragastrically with $0.5 \mathrm{ml}$ of $50 \%$ acetone in water for 4 consecutive days. Twenty four hours after the last treatment, the mice were killed by cervical dislocation, their livers were removed and homogenized in $0.25 \mathrm{M}$ sucrose/0.05 M Tris buffer (pH 7.5), containing $0.025 \mathrm{M} \mathrm{KCl}$ and $0.003 \mathrm{M} \mathrm{MgCl}_{2}$. The livers from 6 animals were pooled and microsomes were prepared by differential centrifugation as described by Gnojkowski et al. (1984). Protein concentrations were determined by the method of Lowry et al. (1951).

PNPH assay. The PNPH activity was measured by determining $p$-nitrocatechol formation, according to the procedure described by Reinke \& Moyer (1985). The reaction mix- tures ( $2 \mathrm{ml}$ total volume) contained acetone induced microsomes (0.7 mg protein), p-nitrophenol $(0.2 \mathrm{mM})$, an NADPH generating system (7.5 mM glucose-6-phosphate, 2 units $/ \mathrm{ml}$ of glucose-6-phosphate dehydrogenase, 0.4 $\mathrm{mM} \mathrm{NADP}^{+}, 5 \mathrm{mM} \mathrm{MgCl}_{2}$ ), $100 \mathrm{mM}$ potassium phosphate buffer ( $\mathrm{pH}$ 6.8) and various concentrations of the tested compounds. Tannic acid was added as a water solution, whereas trans-resveratrol was dissolved in $10 \% \mathrm{Me}_{2} \mathrm{SO}$. The final concentration of $\mathrm{Me}_{2} \mathrm{SO}$ in the preincubation mixture did not exceed $0.1 \%$. At this concentration $\mathrm{Me}_{2} \mathrm{SO}$ did not affect CYP2E1 catalytic activity. Control incubations did not contain the tested compounds. The reaction was initiated by the addition of $\mathrm{NADP}^{+}$and terminated after $30 \mathrm{~min}$ incubation at $37^{\circ} \mathrm{C}$ by the addition of $0.5 \mathrm{ml}$ of trichloroacetic acid. Samples were centrifuged for $15 \mathrm{~min}$ at $13000 \times \mathrm{g}$ and $0.1 \mathrm{ml}$ of $10 \mathrm{M}$ sodium hydroxide was added to $1.5 \mathrm{ml}$ of supernatant. Formation of the product (p-nitrocatechol) was measured at $526 \mathrm{~nm}$, using the molar absorption coefficient of $p$-nitrocatechol equal $9.53 \mathrm{mM}^{-1} \mathrm{~cm}^{-1}$. The percent inhibition of the enzyme activity by the phenolics was calculated and $\mathrm{IC}_{50}$ values were determined graphically, using the Microsoft Excel software program. IC $_{50}$ values represent an average of two separate experiments.

Inhibition kinetics. The enzyme assay was as described in the preceding section. Inhibition constants $\left(K_{\mathrm{i}}\right)$ were determined for two concentrations of the tested compounds and the substrate range from $0.02-0.2 \mathrm{mM}$. The $K_{\mathrm{i}}$ value was determined from double reciprocal plots of the enzyme activity versus substrate concentration (Voet \& Voet 1995).

Inactivation of PNPH. A two-stage incubation procedure was used to examine the time-dependent inactivation of PNPH. trans-Resveratrol and tannic acid (at the concentrations indicated in each figure legend) or the appropriate vehicle (control) were preincubated (first stage incubation) with mouse liver microsomes (3.5 $\mathrm{mg} \operatorname{protein} / \mathrm{ml}$ ) 
and $1 \mathrm{mM}$ NADPH in $100 \mathrm{mM}$ potassium phosphate buffer ( $\mathrm{pH} 6.8$ ) at $37^{\circ} \mathrm{C}$. At various time points, $0.2 \mathrm{ml}$ aliquots were removed and added to $1.8 \mathrm{ml}$ of the secondary reaction mixture to determine the hydroxylase activity. The second-stage incubation was carried out according to the procedure of the PNPH assay. All the assays were run in triplicate and the coefficient of variation was usually less than $10 \%$.

\section{RESULTS AND DISCUSSION}

This study was designed to evaluate selected, naturally occurring phytophenols for their ability to modulate cytochrome P450 2E1 mediated enzyme activity. For this purpose, we have assumed that the predominant cytochrome $\mathrm{P} 450$ mediating PNPH activity is CYP2E1 (Koop et al., 1989, Kobayashi et al., 2002). This $P 450$ isoform is involved in the metabolism of several xenobiotics, including chemical carcinogens. Therefore, its modulation can dramatically affect the compound's toxicity and carcinogenesis.

The effects of protocatechuic acid, tannic acid and trans-resveratrol on hepatic PNPH in mouse microsomes are presented in Fig. 2. The inhibition curves for each compound and $\mathrm{IC}_{50}$ values were determined within different concentration ranges depending on the compound. Protocatechuic acid within the concentration range 0.05 to $5 \mathrm{mM}$ did not inhibit the activity of PNPH. At a lower concentration ( $<1 \mathrm{mM})$, even a slight stimulation of PNPH activity was observed (Panel A). Tannic acid was more potent $\left(\mathrm{IC}_{50}=29.6 \pm 3.3 \mu \mathrm{M}\right)$ and trans-resveratrol was the most potent inhibitor of PNPH activity $\left(\mathrm{IC}_{50}=18.5 \pm 0.4 \mu \mathrm{M}\right)$.

These two compounds were further studied for both the mode and the type of inhibition. For this purpose various concentrations of the substrate were examined at two inhibitor concentrations. Lineweaver-Burk plots were then generated from the resulting data sets. The results of these analyses are presented in Fig. 3.
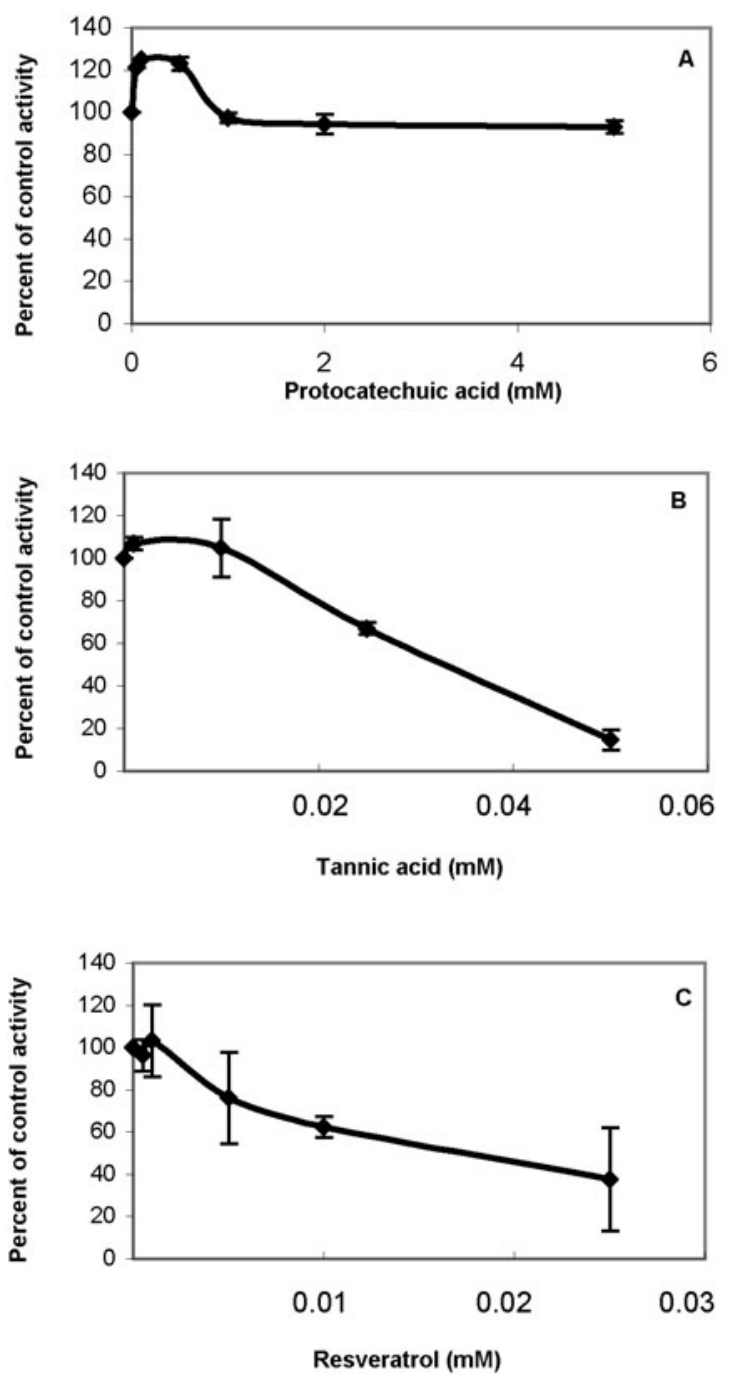

Figure 2. Concentration-dependent inhibition of p-nitrophenol hydroxylation by: protocatechuic acid (A), tannic acid (B) and trans-resveratrol (C).

Data are expressed as mean \pm S.D. percentage of control enzyme activity for three independent experiments. PNPH activity for the control experiment was $0.0017 \pm 0.0003 \mu$ moles $p$-nitrocatechol $/ \mathrm{min}$ per $\mathrm{mg}$ protein.

Tannic acid is a mixed $\left(K_{i}=1 \mu \mathrm{M}\right)$ and trans-resveratrol a competitive PNPH inhibitor $\left(K_{i}=2.1 \mu \mathrm{M}\right)$.

A two-stage incubation procedure (Cai et al., 1993) was utilized to examine the ability of these phenolics to inactivate the enzymatic activities associated with hepatic microsomal PNPH. These results are presented in Fig. 4 and show that only trans-resveratrol (panel B) possessed the ability to inactivate microsomal 
A

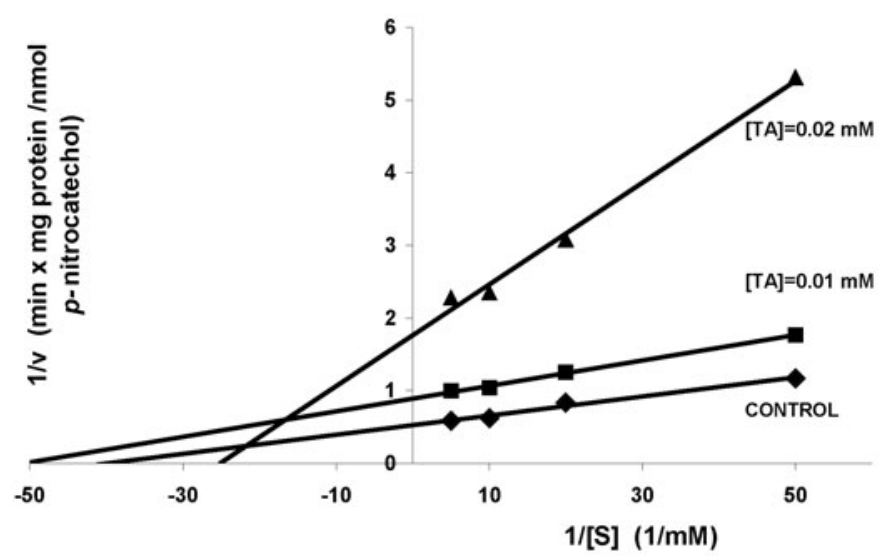

B

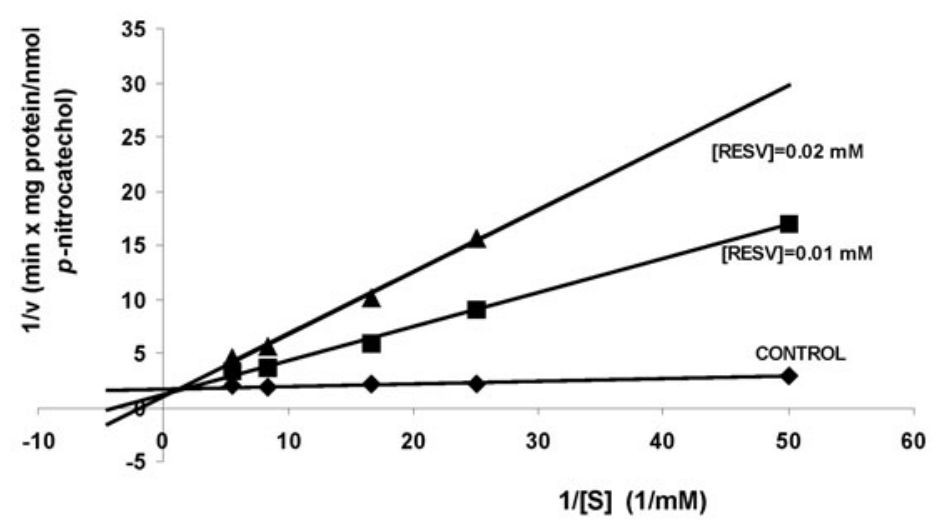

Figure 3. Inhibition of mouse liver CYP2E1 activity by tannic acid (A) and trans-resveratrol (B).

Lineweaver-Burk plots for the inhibition of $p$-nitrophenol hydroxylase in mouse liver microsomes. $p$-Nitrophenol was used in the range of concentration 0.02-0.2 mM. Values are means of triplicate determinations. Coefficient of variation did not exceed $6.6 \%$.
PNPH with $k_{\text {inactivation }}$ equal $0.06 \mathrm{~min}^{-1}$. No inactivation of PNPH activity was detectable in the absence of NADPH (data not shown).

Until now, a number of compounds have been reported as selective inhibitors of cytochrome(s) P450, including both reversible and mechanism-based inactivators. For example, naturally occurring coumarins, found in human diet, demonstrated a structure-activity relationship for $\mathrm{P} 450$ selectivity and the type or mode of inhibition (Cai et al., 1993). Among them, coriandrin was found to be a potent inhibitor and inactivator of murine and purified human P450 1A1 (Cai et al., 1993). The selective inhibition of P450 2E1 by diallyl sulfide and phenethyl isothiocyanate, the components of Allium sp. and Brassicaceae vegetables, was also reported (Guyonnet et al., 2000; Nakajima et al., 2001; Yang et al., 1994). On the other hand, effective inhibitors of carcinogenesis are known which are not selective inhibitors of cytochromes P450. An exam- ple of this group is chlorophyllin, which nonspecifically inhibits several CYP-mediated activities (Yun et al., 1995).

The phenolic compounds examined in the present study rather represent the non-selective group of P450 inhibitors. In our previous studies, tannic acid inhibited mouse hepatic cytochromes $\mathrm{P} 450$ 1A1, $1 \mathrm{~A} 2$ and $2 \mathrm{~B}$ mediated enzyme activities in vitro even to a greater extent $\left(\mathrm{IC}_{50} 2.6-7 \mu \mathrm{M}\right.$ ) than CYP2E1 in the current study (Baer-Dubowska et al., 1998; Das et al., 1987). As in this report, tannic acid was also a mixed inhibitor of pentoxyresorufine O-dealkylase (CYP 2B), suggesting that tannic acid may bind not only to the substrate binding site of both enzymes but also to an additional site that causes a loss of enzyme activity. Protocatechuic acid, which did not show any effect on the activity of PNPH in the current study, was shown to be an efficient inhibitor of methoxy- and pentoxyresorufin O-dealkylases, the enzy- 

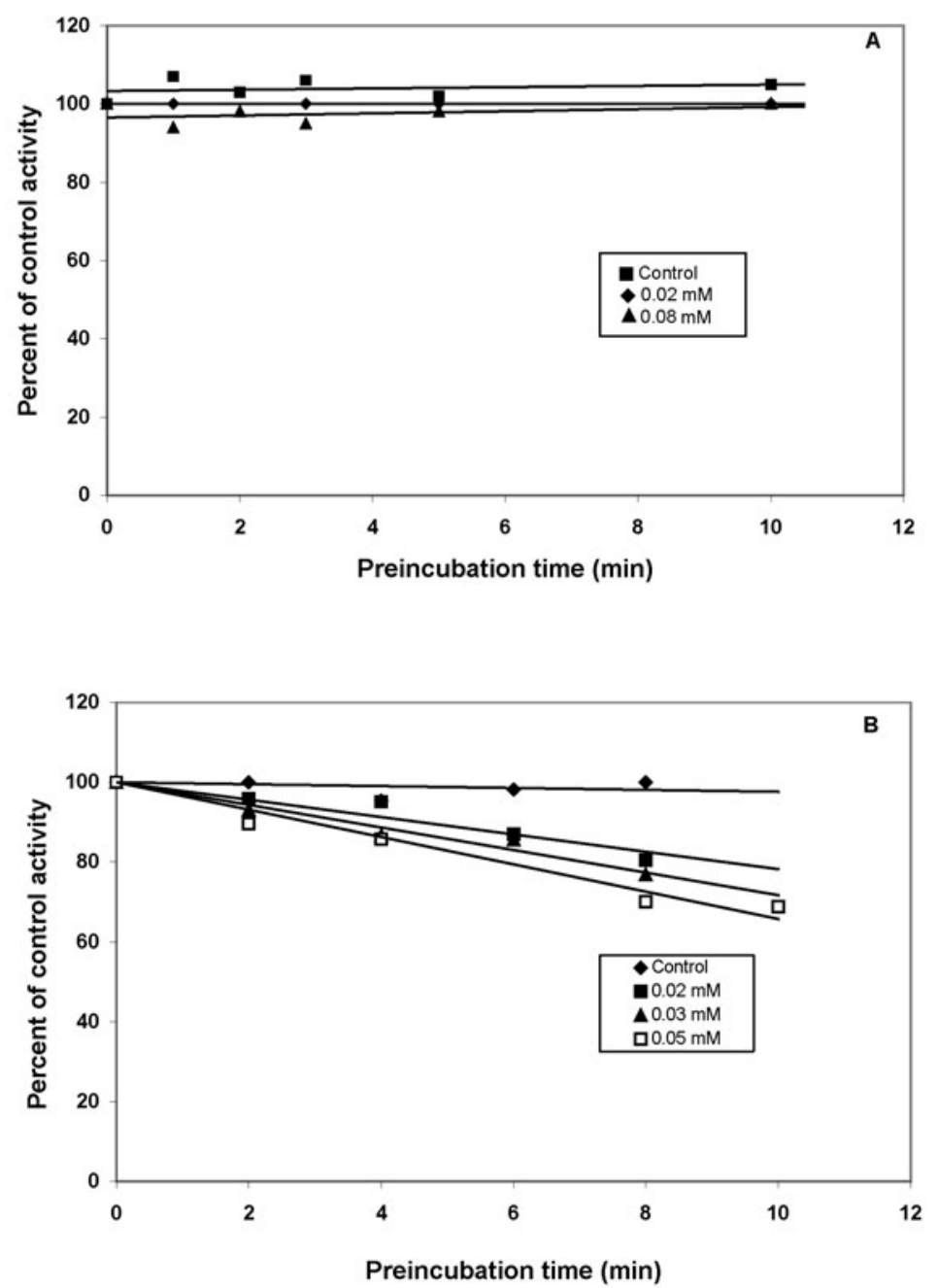

Figure 4. Inactivation of CYP2E1 by tannic acid (A) and trans-resveratrol (B) in mouse liver microsomes.

Mouse liver microsomes were preincubated with varying concentrations of inactivators as described under Materials and Methods. Each point represents the mean percentage of control activity of three experiments. Coefficient of variation did not exceed $9.2 \%$.

matic markers of CYP1A2 and 2B, respectively (Baer-Dubowska et al., 1998). In vivo, induction of CYP1A is controlled by aryl hydrocarbon receptor (AhR). trans-Resveratrol, the most potent inhibitor of PNPH in the present study, was shown to block CYP1A1 transcription in human HepG2 hepatoma cells by preventing the receptor from binding to the enhancer sequences of the CYP1A1 promoter, that regulate the transcription of the gene (Ciolino et al., 1998). Moreover, inhibition of human CYP1A1 and the other AhR gene battery products, cytochromes $1 \mathrm{~B} 1$ and $1 \mathrm{~A} 2$ by resveratrol was also demonstrated (Chun et al., 1999; Chang et al., 2000). Thus AhR might be a potential target for all the phytophenols examined in this paper study for modulating carcinogen activation. However, the results of this study indicate that, especially for trans-resveratrol, an inhibition of P450 2E1 might be equally important. Moreover, trans-resveratrol was also reported to inhibit human recombinant CYP3A4 and CYP3A5 in vitro (Chang \& Yeung, 2001). In our studies, trans-resveratrol was a competitive inhibitor of PNPH. This is in contrast to the observation of Piver et al. (2001), who demonstrated that trans-resveratrol and red wine solid components act as non-competitive inhibitors of CYP2E1 activity in rat and human liver microsomes. In their studies, however, chlorzoxazone 6-hydroxylation was used as an enzymatic marker of the catalytic activity of CYP2E1, so the difference in the mechanism of inhibition may be explained by the existence of more than one active site specific for different substrates.

Our present study also showed the ability of trans-resveratrol to inactivate cytochrome P450 2E1 in a mechanism-based manner. The 
requirement for $\mathrm{NADPH}$ in the trans-resveratrol inactivation of CYP2E1 indicates that it is not trans-resveratrol, but a reactive intermediate that is responsible for the inactivation of this enzyme. Mechanism-based inactivation of CYP1A2 by trans-resveratrol has also been reported (Chang et al., 2001). More detailed studies, which are underway, are necessary to explore the mechanism(s) of the inactivation of specific cytochromes $\mathrm{P} 450$ by this naturally occurring polyphenol. The nature of the metabolite formed in the biotransformation of trans-resveratrol catalysed by CYP2E1 remains to be identified as well. The metabolic hydroxylation of trans-resveratrol by CYP1B1 recently reported by Potter et al. (2002) demonstrates that trans-resveratrol can be converted to piceatannol, a tyrosine kinase inhibitor and a compound of known anticancer activity (Geahlen \& McLaughlin, 1989).

In conclusion, our studies show that tannic acid and trans-resveratrol are potent inhibitors of CYP2E1 activity in mouse liver microsomes, but they affect this cytochrome in different ways. Future studies will focus on the mechanism of interaction and modulation of these structurally diverse polyphenols with carcinogen metabolizing enzymes.

\section{R E F E R E N C E S}

Baer-Dubowska W, Gnojkowski J, Fenrych W. (1997) Effect of tannic acid on benzo[a]pyrene-DNA adduct formation in mouse epidermis: comparison with synthetic gallic acid esters. Nutr Cancer; 29: 42-7.

Baer-Dubowska W, Szaefer H, Krajka-Kuźniak V. (1998) Inhibition of murine hepatic cytochrome $\mathrm{P} 450$ activities by natural and synthetic phenolic compounds. Xenobiotica.; 28: $735-43$.

Burns J, Yokota T, Ashihara H, Lean MEJ, Crozier A. (2002) Plant foods and herbal sources of resveratrol. J Agric Food Chem.; 50: 3337-40.
Cai Y, Bennett D, Nair RV, Ceska O, Ashwood-Smith MJ, DiGiovanni J. (1993) Inhibition and inactivation of murine hepatic ethoxy- and pentoxyresorufin O-dealkylase by naturally occurring coumarins. Chem Res Toxicol.; 6: 872-9.

Chang TKH, Lee WBK, Ko HH. (2000)

Trans-resveratrol modulates the catalytic activity and mRNA expression of the procarcinogen-activating human cytochrome P450 1B1. Can J Physiol Pharmacol.; 78: 874-81.

Chang TKH, Yeung RKY. (2001) Effect of trans-resveratrol on 7-benzyloxy-4-trifluoromethylcoumarin O-dealkylation catalyzed by human recombinant CYP3A4 and CYP3A5. Can J Physiol Pharmacol.; 79: 220-26.

Chang TKH, Chen J, Lee WBK. (2001) Differential inhibition and inactivation of human CYP1 enzymes by trans-resveratrol: evidence for mechanism-based inactivation of CYP1A2. J Pharmacol Exp Ther;; 299: 874-82.

Chen S-C, Chung K-T. (2000) Mutagenicity and antimutagenicity studies of tannic acid and its related compounds. Food Chem Toxicol.; 38: $1-5$.

Chun YJ, Kim, MY, Guengerich P. (1999) Resveratrol is a selective human cytochrome P450 1A1 inhibitor. Biochem Biophys Res Commun.; 262: 20-4.

Ciolino HP, Daschner PJ, Yeh GC. (1998) Resveratrol inhibits transcription of CYP1A1 in vitro by preventing activation of aryl hydrocarbon receptor. Cancer Res.; 58: 5707-12.

Das DK, Sato M, Ray PS, Maulik G, Engelman RM, Bertelli AA, Bertelli A. (1999) Cardioprotection of red wine: role of polyphenolic antioxidants. Drug Exp Clin Res.; 25: 115-20.

Geahlen RL, McLaughlin JL. (1989) Isolation of piceatannol as the antileukemic principle from the seeds of euphorbia lagascae. Biochem Biophys Res Commun.; 165: 241-45.

Gnojkowski J, Baer-Dubowska W, Klimek D, Chmiel J. (1984) Effect of toluidines on drug 
metabolizing enzymes. Toxicology.; 32: $335-42$.

Guengerich FP, Kim DH, Iwasaki M. (1991) Role of human cytochrome P-450 IIE1 in the oxidation of many low molecular weight cancer suspects. Chem Res Toxicol.; 4: 168-79.

Guengerich FP, Shimada T. (1998) Activation of procarcinogens by human cytochrome P450 enzymes. Mutat Res.; 400: 201-213.

Gusman J, Malonne H, Atassi G. (2001) A reappraisal of the potential chemopreventive and chemotherapeutic properties of resveratrol. Carcinogenesis.; 22: 1111-17.

Guyonnet D, Belloir C, Suschetet M, Siess M-H, Le Bon A-M. (2000) Liver subcellular fractions from rats treated by organosulfur compounds from Allium modulate mutagen activation. Mutat Res.; 466: 17-26.

Hursting SD, Slaga TJ, Fisher SM, DiGiovanni J, Phang JM. (1999) Mechanism-based cancer approaches: targets, examples, and use of transgenic mice. J Natl Cancer Inst.; 91: 215-25.

Ignatowicz E, Baer-Dubowska W. (2001) Resveratrol, a natural chemopreventive agent against degenerative diseases. $\mathrm{Pol} J$ Pharmacol.; 53: 557-69.

Jang M, Cai L, Udeani GO, Slowing KV, Thomas CF, Beecher CW, Fong HHS, Farnsworth NR, Kinghorn DA, Mehta RG, Moon RC, Pezzuto JM. (1997) Cancer chemopreventive activity of resveratrol, a nature product derived from grapes. Science,; 275: 218-20.

Kobayashi K, Urashima K, Shimada N, Chiba K. (2002) Substrate specificity for rat cytochrome P450 (CYP) isoforms: screening with cDNA-expressed systems of the rat. Biochem Pharmacol.; 63: 889-96.

Koop DR, Laethem CL, Tierney DJ. (1989) The utility of $p$-nitrophenol hydroxylation in P450IIE1 analysis. Drug Metab Rev.; 20: 541-51.

Lowry OH, Rosebrough NJ, Farr AL, Randall RJ. (1951) Protein measurement with the Folin phenol reagent. J Biol Chem.; 193: $230-65$.
Li ZG, Hong T, Shimada Y, Komoto I, Kawabe A, Ding Y, Kaganoi J, Hashimoto Y, Imamura M. (2002) Suppression of $\mathrm{N}$-nitrosomethylbenzylamine (NMBA)-induced esophageal tumorigenesis in F344 rats by resveratrol. Carcinogenesis.; 23: 1531-6.

Mori H, Matsunaga K, Tanakamaru Y, Kawabata K, Yamada Y, Sugie S, Nishikawa A. (1999) Effects of protocatechuic acid, $S$-methylmethanethiosulfonate or 5-hydroxy4-(2-phenyl-(E)ethenyl)-2(5H)-furanone (KYN-54) on 4-(methylnitrosoamino)-1-(3pyridyl)-1-butanone-induced pulmonary carcinogenesis in mice. Cancer Lett.; 135: 123-27.

Nakajima M, Yoshida R, Shimada N, Yamazaki H, Yokoi T. (2001) Inhibition and inactivation of human cytochrome P450 isoforms by phenethyl isothiocyanate. Drug Metab Dispos.; 29: 1110-3.

Nakamura H, Nishikawa A, Furukawa F, Kasahara K, Miyauchi M, Son H-Y, Hirose M. (2000) Inhibitory effects of protocatechuic acid on the post-initiation phase of hamster pancreatic carcinogenesis induced by $N$-nitrosobis(2-oxopropyl)amine. Anticancer Res.; 20: 3423-7.

Nepka C, Asprodini E, Kouretas D. (1999) Tannins, xenobiotic metabolism and cancer chemoprevention in experimental animals. Eur J Drug Metab Pharmacokinet.; 24: 183-9.

Newmark HL. (1987) Plant phenolics as inhibitors of mutational and precarcinogenic events. Can J Physiol Pharmacol.; 65: 461-6.

Ohnishi M, Yoshimi N, Kawamori T, Ino N, Hirose Y, Tanaka T, Yamahara J, Miyata H, Mori H. (1997) Inhibitory effects of dietary protocatechuic acid and costunolide on 7,12-dimethylben[a]anthracene-induced hamster cheek pouch carcinogenesis. Jpn J Cancer Res.; 88: 111-9.

Piver B, Berthou F, Dreano Y, Lucas D. (2001) Inhibition of CYP3A, CYP1A and CYP2E1 activities by resveratrol and other non volatile red wine components. Toxicol Lett.; 125: 83-91. 
Potter GA, Patterson LH, Wanogho E, Perry PJ, Butler PC, Iliaz T, Ruparelia KC, Lamb JH, Farmer PB, Stanley LA, Burke MD. (2002) The cancer preventative agent resveratrol is converted to the anticancer agent piceatannol by the cytochrome P450 enzyme CYP1B1. Br J Cancer:; 86: 774-8.

Reinke LA, Moyer MJ. (1985) p-Nitrophenol hydroxylation - a microsomal oxidation which is highly inducible by ethanol. Drug Metab Dispos.; 13: 548-52.

Soleas GJ, Diamandis EP, Golberg DM. (1997) Wine as a biological fluid: history, production, and role in disease prevention. J Clin Lab Anal.; 11: 287-313.

Soleas GJ, Grass L, Josephy PD, Goldberg DM, Eleftherios P. (2002) A comparison of the anticarcinogenic properties of four wine poly phenols. Clin Biochem.; 35: 119-24.

Sporn MB, Suh N. (2000) Chemoprevention of cancer. Carcinogenesis.; 21: 525-30.
Uenobe F, Nakamura S, Miyazawa M. (1997) Antimutagenic effect of resveratrol against Trp-P-1. Mutat Res.; 373: 197-200.

Voet D, Voet JG. (1995) Rates of enzymatic reactions. In Biochemistry. Ardwin L, Ingrao S. eds, pp 355-60, John Wiley \& Sons, Inc., New York.

Yang CS, Smith TJ, Hong J-Y. (1994) Cytochrome P450 enzymes as targets for chemoprevention against chemical carcinogenesis and toxicity: opportunities and limitations. Cancer Res (Suppl).; 54: 1982s-6s.

Yun C-H, Jhoun JW, Guengerich FP. (1995) Non-specific inhibition of cytochrome P450 activities by chlorophyllin in human and rat liver microsomes. Carcinogenesis.; 16: 1437-40. 